\title{
Association of the brain-derived neurotrophic factor val66met polymorphism with magnetic resonance spectroscopic markers in the human hippocampus: in vivo evidence for effects on the glutamate system
}

\author{
Oliver Gruber • Alkomiet Hasan · Harald Scherk • Thomas Wobrock • \\ Thomas Schneider-Axmann · Savira Ekawardhani • Andrea Schmitt • \\ Martin Backens $\cdot$ Wolfgang Reith $\cdot$ Jobst Meyer $\cdot$ Peter Falkai
}

Received: 24 November 2010/Accepted: 8 April 2011/Published online: 21 April 2011

(C) The Author(s) 2011. This article is published with open access at Springerlink.com

\begin{abstract}
The brain-derived neurotrophic factor (BDNF) is a key regulator of synaptic plasticity and has been suggested to be involved in the pathophysiology and pathogenesis of psychotic disorders, with particular emphasis on dysfunctions of the hippocampus. The aim of the present study was to replicate and to extend prior findings of BDNF val66met genotype effects on hippocampal volume and N-acetyl aspartate (NAA) levels. Hundred and fiftyeight caucasians (66 schizophrenic, 45 bipolar, and 47 healthy subjects; 105 subjects underwent MRI and 103 MRS scanning) participated in the study and were genotyped with regard to the val66met polymorphism (rs6265) of the BDNF gene. Hippocampal volumes were determined using structural magnetic resonance imaging (MRI), and measures of biochemical markers were taken using proton magnetic resonance spectroscopy $\left({ }^{1} \mathrm{H}-\mathrm{MRS}\right)$ in the
\end{abstract}

O. Gruber and A. Hasan contributed equally.

Preliminary results described in this paper were presented at the Human Brain Mapping Conference, San Fransisco (USA), June 18th23rd 2009 and at the 3rd meeting of Western European Societies of Biological Psychiatry, Berlin (Germany), June 2nd-4th 2010.

O. Gruber · A. Hasan $(\varangle) \cdot$ H. Scherk · T. Wobrock ·

T. Schneider-Axmann · A. Schmitt · P. Falkai

Department of Psychiatry and Psychotherapy,

Georg August University Göttingen, Von-Siebold-Strasse 5,

37075 Göttingen, Germany

e-mail: ahasan@gwdg.de

M. Backens · W. Reith

Department of Neuroradiology, Saarland University Homburg, 66421 Homburg/Saar, Germany

S. Ekawardhani $\cdot$ J. Meyer

Department of Neurobehavioral Genetics, University of Trier, 54290 Trier, Germany hippocampus and other brain regions. Verbal memory was assessed as a behavioral index of hippocampal function. BDNF genotype did not impact hippocampal volumes. Significant genotype effects were found on metabolic markers specifically in the left hippocampus. In particular, homozygous carriers of the met-allele exhibited significantly lower NAA/Cre and (Glu + Gln)/Cre metabolic ratios compared with val/val homozygotes, independently of psychiatric diagnoses. BDNF genotype had a numerical, but nonsignificant effect on verbal memory performance. These findings provide first in vivo evidence for an effect of the functional BDNF val66met polymorphism on the glutamate system in human hippocampus.

Keywords Genetics - Magnetic resonance spectroscopy · Neuroimaging · Glutamate $\cdot$ Schizophrenia $\cdot$ Bipolar disorder · Hippocampal plasticity

\section{Introduction}

Brain-derived neurotrophic factor (BDNF) modulates hippocampal plasticity, hippocampal-dependent memory and has been suggested to be involved in the pathophysiology of different mental disorders [10, 17, 43]. In particular, a close relationship appears to exist between BDNF and schizophrenia [27] and affective disorders [40], implicating that BDNF may be a candidate gene for these mental disorders. BDNF acts as a vital trophic protein for neuronal survival and differentiation in the developing nervous system [22] and modulates cholinergic, dopaminergic, and serotonergic neurons, which may also have an impact on the etiopathogenesis of mental disorders [13, 38, 41]. Recent studies revealed an important role of BDNF in the regulation of glutamatergic synapses and glutamate 
receptor activity [6], which may represent one important link between BDNF and hippocampal function. Glutamate receptor function is essential for memory functions, and the hippocampal pyramidal layers are densely packed with glutamate-containing excitatory neurons. These neurons are involved in the induction of long-term potentiation (LTP) and long-term depression (LTD), which are the cellular and molecular mechanisms underlying memory [29, 42].

The gene encoding human BDNF is localized to chromosome 11 , band p13 and it encodes a precursor peptide (proBDNF), which is cleaved to form the mature protein via proteolyses [10, 28]. It was shown that the frequent nonconservative amino acid substitution valine to methionine on codon 66 (val66met-polymorphism, dbSNP number rs6265) in the $5^{\prime}$ signal domain of BDNF gene leads to disturbances in the intracellular packaging and regulated secretion of $\mathrm{BDNF}$ without affecting mature BDNF protein function [10]. In normal individuals, this frequent polymorphism (met-allele carriers) has been shown to affect human hippocampal function, episodic memory, and declarative memory [7, 10, 17, 19]. In particular, previous studies revealed smaller hippocampal volume in met-allele carriers independent of age and gender in healthy subjects $[5,37]$. Studies using magnetic resonance spectroscopic imaging (MRS) reported an association between the functional BDNF val66met polymorphism and reduced hippocampal $\mathrm{N}$-acetyl aspartate (NAA) [10, 41].

The aims of the present study were, first, to replicate and extend prior findings of BDNF effects on hippocampal volume [5, 37] and NAA [10, 41] by assessing the effect of the BDNF val66met polymorphism in a large and ethnically homogeneous sample including healthy individuals and psychiatric patients suffering from psychotic disorders (schizophrenia and bipolar affective disorder, heterogeneous clinical status). Second, we sought to provide empirical evidence for the hypothesis that the BDNF val66met polymorphism may also impact on glutamatergic mechanisms in the human hippocampus [6, 41]. For these purposes, we determined hippocampal brain volumes using structural magnetic resonance imaging (MRI) and performed in vivo measures of hippocampal NAA, choline, creatine, and glutamate/glutamine using proton magnetic resonance spectroscopy $\left({ }^{1} \mathrm{H}-\mathrm{MRS}\right)$. Furthermore, in order to address memory indices of hippocampal function, subjects were tested with the verbal learning memory test (VLMT, [35]). Based on the results of prior studies, we hypothesized that carriers of the met-allele (val/met, met/ met genotype) would reveal lower $\mathrm{N}$-acetyl aspartate and glutamate levels, lower hippocampal gray matter volume, and worse memory performance in the VLMT than val/val homozygotes.

\section{Materials and methods}

\section{Subjects}

Sixty-six patients suffering from schizophrenia (SZ), 45 patients with bipolar I disorder (BP), and 47 healthy controls participated in the study. All subjects were recruited from the Saarland area, and all of them were Caucasians of European ancestry (most German). A subsample of these subjects underwent MRI $(n=105)$ or MRS ( $n=103$ ) scanning. All patients provided informed consent before entering the study, and the study design was approved by the local ethics committee. Diagnoses were based on the German version of the Structural Clinical Interview for DSM IV [44] and were consented within members of the study group and the treating clinical psychiatrist, who was blind to the aims of the study. Patients were excluded from the study if they met any of the following criteria: organic central nervous system disorder (e.g., epilepsy, traumatic brain injury, infectious, toxic, or cerebrovascular disease), mental retardation, or inadequate knowledge of the German language. At the time of the study, most patients received, depending on the disease, a stable medication, including typical and atypical neuroleptics, mood stabilizers, and benzodiazepines. Healthy control subjects exhibited no past or present psychiatric, neurological or medical disorder and had no positive family history of psychiatric disorders. Demographic data for the study sample are given in Table 1. Clinical characteristics and psychopathological scores for the patient groups are presented in Table 2 .

\section{MRI acquisition and volumetric measurement}

MRI scanning was performed on a 1.5-Tesla Magnetom Sonata (Siemens, Erlangen). A T1-weighted, magnetization prepared rapid gradient echo sequence (MPRAGE) (echo time, $\mathrm{TE}=4 \mathrm{~ms}$; repetition time, $\mathrm{TR}=1.900 \mathrm{~ms}$; inversion time, $\mathrm{TI}=700 \mathrm{~ms}$, flip angle $=15^{\circ}$, image matrix $=256 \times 256 \mathrm{~mm}$ ) generating 176 consecutive sagittal slices with a voxel size of $1 \mathrm{~mm}^{3}$ was acquired. Image processing and analysis used the software packages Analyze (Mayo Foundation, 1999), Statistical Parametric Mapping (SPM99, Institute of Neurology, London, UK, [2], exclusively used in order to determine total gray matter volume) as well as interactive data language applications (IDL) generated in our imaging lab. First, the MR images were realigned in parallel to the AC-PC (anterior commissure and posterior commissure) plane. As described previously [14], hippocampal morphometry in all participants was conducted manually by raters (hand tracing) who were blind to diagnosis and genotype. Hippocampal 
Table 1 Demographic and clinical data of study subjects

\begin{tabular}{|c|c|c|c|c|c|}
\hline Variable & $\mathrm{Val} / \mathrm{val}$ & $\mathrm{Val} / \mathrm{met}$ & Met/met & Statistic & $P$ \\
\hline \multicolumn{6}{|l|}{ All subjects } \\
\hline$N$ & 94 & 56 & 8 & & \\
\hline Gender & $39 \mathrm{M}, 55 \mathrm{~F}$ & $36 \mathrm{M}, 20 \mathrm{~F}$ & $6 \mathrm{M}, 2 \mathrm{~F}$ & $\chi^{2}(2)=9.2$ & 0.01 \\
\hline Age (years; \pm SD) & $37.6 \pm 11.7$ & $38.8 \pm 13.3$ & $39.5 \pm 14.7$ & $\mathrm{~F}(2,155)=0.2$ & 0.81 \\
\hline Education (years; $\pm \mathrm{SD}$ ) & $13.7 \pm 3.0$ & $13.6 \pm 2.9$ & $14.0 \pm 3.5$ & $\mathrm{~F}(2,155)=0.1$ & 0.95 \\
\hline Diagnosis: control subjects $(N)$ & 27 & 16 & 4 & $\chi^{2}(4)=3.2$ & 0.52 \\
\hline Diagnosis: schizophrenia $(N)$ & 43 & 21 & 2 & & \\
\hline Diagnosis: bipolar disorder $(N)$ & 24 & 19 & 2 & & \\
\hline \multicolumn{6}{|l|}{ Subjects with hippocampal MRI data } \\
\hline$N$ & 60 & 41 & 4 & & \\
\hline Gender & $26 \mathrm{M}, 34 \mathrm{~F}$ & $28 \mathrm{M}, 13 \mathrm{~F}$ & $2 \mathrm{M}, 2 \mathrm{~F}$ & $\chi^{2}(2)=6.1$ & 0.047 \\
\hline Age (yrs; \pm SD) & $38.03 \pm 12.1$ & $37.82 \pm 13.8$ & $48.53 \pm 13.0$ & $\mathrm{~F}(2,102)=1.3$ & 0.28 \\
\hline Education (years; \pm SD) & $13.84 \pm 2.97$ & $13.78 \pm 2.8$ & $15.25 \pm 3.2$ & $\mathrm{~F}(2,102)=0.5$ & 0.62 \\
\hline Diagnosis: control subjects $(N)$ & 24 & 12 & 3 & $\chi^{2}(4)=5.48$ & 0.24 \\
\hline Diagnosis: schizophrenia $(N)$ & 20 & 12 & 0 & & \\
\hline Diagnosis: bipolar disorder $(N)$ & 16 & 17 & 1 & & \\
\hline \multicolumn{6}{|c|}{ Subjects with hippocampal MRS data } \\
\hline$N$ & 61 & 38 & 4 & & \\
\hline Gender & $28 \mathrm{M}, 33 \mathrm{~F}$ & $28 \mathrm{M}, 10 \mathrm{~F}$ & $2 \mathrm{M}, 2 \mathrm{~F}$ & $\chi^{2}(2)=7.4$ & 0.025 \\
\hline Age (years; \pm SD) & $38.22 \pm 12.3$ & $37.48 \pm 13.6$ & $48.53 \pm 13.1$ & $\mathrm{~F}(2,100)=1.35$ & 0.26 \\
\hline Education (years; \pm SD) & $13.74 \pm 2.86$ & $13.97 \pm 2.71$ & $15.25 \pm 3.2$ & $\mathrm{~F}(2,100)=0.57$ & 0.57 \\
\hline Diagnosis: control subjects $(N)$ & 23 & 11 & 3 & $\chi^{2}(4)=4.62$ & 0.33 \\
\hline Diagnosis: schizophrenia $(N)$ & 22 & 13 & 0 & & \\
\hline Diagnosis: bipolar disorder $(N)$ & 16 & 14 & 1 & & \\
\hline
\end{tabular}

Data are presented as mean \pm standard deviation unless otherwise indicated. Values are expressed as $\chi^{2}$ statistics for categorical variables and $F$ statistics for continuous variables. conv. conventional, $F$ female, $N$ number, $M$ male, and $S D$ standard deviation

contours were drawn in the sagittal view using the "region of interest" tool implemented in the software Analyze. After having completed the drawing for all sagittal slices in which the hippocampus was visible, the correctness of the contours was controlled in the coronal and horizontal views. Subsequently, both the hippocampal volumes as marked by the two-dimensional drawings and the total brain volumes were determined using an automatic algorithm programmed in MATLAB and SPM99. Because we were interested in specific effects on the size of the hippocampus independent from total brain volumes, statistical analysis was performed on relative hippocampal volumes expressed by the quotient of hippocampal and total brain volume.

Proton magnetic resonance spectroscopy

As described previously [39], single-volume ${ }^{1} \mathrm{H}-\mathrm{MRS}$ was performed on a 1.5-Tesla Siemens Magnetom Sonata (Siemens, Erlangen) using a spin-echo sequence with water suppression and 128 scan averages $(\mathrm{TE}=30$, $\mathrm{TR}=1.500$ ). Regions of interest were defined in the left hippocampus, in the middle third of the left middle frontal gyrus (referred to as left dorsolateral prefrontal cortex), and in the left posterior frontomedian cortex along the cingulate sulcus. These regions were determined according to an exactly predefined and standardized algorithm with multiple rechecking procedures in a $T 2$ gradient echo image (TrueFISP) with 24 slices each in three orthogonal orientations. The positions of the voxels were visually inspected and adjusted based on identifiable anatomical landmarks in reference to standard brain atlases. The voxel sizes were adjusted to the morphology of the anatomical target structures and were $10 \times 35 \times 10 \mathrm{~mm}^{3}$ for the hippocampus (see Fig. 1) and the middle third of the middle frontal gyrus, and $12 \times 20 \times 15 \mathrm{~mm}^{3}$ for the posterior frontomedian cortex.

All spectra were postprocessed by using the Siemens Medical Solutions spectroscopy software package on a Leonardo workstation. Following acquisition, low-frequency 
Table 2 Clinical data and symptom ratings of the patient groups: data are presented as mean \pm standard deviation unless otherwise indicated

\begin{tabular}{|c|c|c|c|c|c|c|c|c|c|c|c|c|}
\hline & \multicolumn{3}{|c|}{$\mathrm{Val} / \mathrm{val}$} & \multicolumn{3}{|c|}{$\mathrm{Val} / \mathrm{met}$} & \multicolumn{3}{|c|}{ Met/met } & \multicolumn{3}{|c|}{ Statistics } \\
\hline & $N$ & Mean & SD & $N$ & Mean & SD & $N$ & Mean & $\mathrm{SD}$ & $d f$ & $F$ & $P$ \\
\hline \multicolumn{13}{|l|}{ Schizophrenia patients (MRS) } \\
\hline CPZ (daily dosage) & 20 & 398.0 & 387.9 & 12 & 204.2 & 143.7 & & & & 1,30 & 2.74 & 0.11 \\
\hline CPZ (cumulative) & 20 & 11,241 & 18,767 & 12 & 3,638 & 3,216 & & & & 1,30 & 1.91 & 0.18 \\
\hline Duration of psychosis (weeks) & 20 & 45 & 62 & 12 & 46 & 39 & & & & 1,30 & 0.00 & 0.98 \\
\hline PANSS positive & 20 & 21.5 & 5.5 & 12 & 22.0 & 6.2 & & & & 1,30 & 0.07 & 0.79 \\
\hline PANSS negative & 20 & 23.2 & 6.6 & 12 & 19.8 & 7.3 & & & & 1,30 & 1.74 & 0.20 \\
\hline PANSS general & 20 & 49.2 & 8.8 & 12 & 43.1 & 8.8 & & & & 1,30 & 3.62 & 0.067 \\
\hline PANSS total & 20 & 93.8 & 15.6 & 12 & 84.9 & 17.6 & & & & 1,30 & 2.22 & 0.15 \\
\hline MADRS total score & 19 & 20.1 & 6.2 & 11 & 15.5 & 5.1 & & & & 1,28 & 4.31 & 0.047 \\
\hline \multicolumn{13}{|l|}{ Bipolar patients (MRS) } \\
\hline Disease duration (years) & 16 & 13.3 & 10.1 & 15 & 13.9 & 12.0 & 1 & 37.0 & & 2,29 & 2.17 & 0.13 \\
\hline MADRS total score & 15 & 4.1 & 3.4 & 15 & 4.6 & 3.1 & 1 & 2.0 & & 2,28 & 0.33 & 0.72 \\
\hline YMRS & 14 & 2.3 & 3.1 & 15 & 3.2 & 2.7 & 1 & 0.0 & & 2,27 & 0.81 & 0.46 \\
\hline Psychotic symptoms (no/yes) & & $11 / 5$ & & & $12 / 3$ & & & $1 / 0$ & & 2 & 0.87 & 0.65 \\
\hline Neuroleptics (none/FG/SG) & & $9 / 1 / 6$ & & & $7 / 2 / 6$ & & & $1 / 0 / 0$ & & 4 & 1.47 & 0.83 \\
\hline Lithium (no/yes) & & $10 / 6$ & & & $10 / 5$ & & & $0 / 1$ & & 2 & 1.78 & 0.41 \\
\hline Other mood stabilizer (no/yes) & & $4 / 12$ & & & $4 / 11$ & & & $0 / 1$ & & 2 & 0.36 & 0.84 \\
\hline Benzodiazepine (no/yes) & & $12 / 3 / 1$ & & & $13 / 2 / 0$ & & & $1 / 0 / 0$ & & 4 & 1.48 & 0.83 \\
\hline Antidepressants (no/yes) & & $13 / 3$ & & & $8 / 7$ & & & $1 / 0$ & & 2 & 3.28 & 0.19 \\
\hline
\end{tabular}

Values are expressed as $\chi^{2}$ statistics for categorical variables and $F$ statistics for continuous variables. $N$ group size, $S D$ standard deviation, $d f$ degrees of freedom, $F F$ statistic, $P$ error probability of first kind, $C P Z$ chlorpromazine equivalent dose, $P A N S S$ positive and negative syndrome scale, MADRS Montgomery-Asberg depression rating scale, YMRS young mania rating scale, $F G$ first-generation antipsychotic drugs, and $S G$ second-generation antipsychotic drugs

Fig. 1 Magnetic resonance imaging (MRI) demonstrating the localization and welladapted shape of the volume of interest (voxel size

$\left.10 \times 35 \times 10 \mathrm{~mm}^{3}\right)$ placed in the left hippocampus (MR images in radiological convention) in a transversal, b coronal, and c sagittal orientation
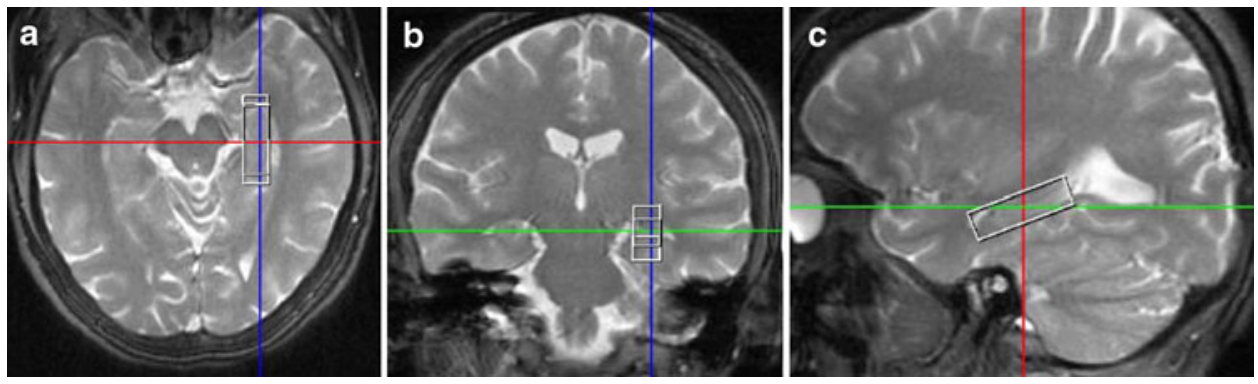

filtering for removal of the residual water signal and correction for frequency shifts were performed. Data were zero-filled from 1.024 to 2.048 points. After apodization of the time domain signal by a Hanning function with $700 \mathrm{~ms}$ width, the data were Fourier transformed to the frequency domain. The spectra were baseline corrected with a sixth-order polynomial and first-order phase-corrected. Curve fitting to the metabolic peaks was applied using Gaussian or Lorentzian line shapes at known frequencies. Relative metabolite concentrations for $\mathrm{N}$-acetyl groups (NAA), choline-containing compounds (Cho), creatine and phosphocreatine (Cre), and glutamate plus glutamine (Glu + Gln) were determined, and the metabolic ratios NAA/Cre, NAA/Cho, Cho/Cre, and (Glu + Gln)/Cre were calculated. A model MRS spectrum from one subject is presented in Fig. 2.

\section{VLMT}

Cognitive performance was measured using the German version of the Rey Auditory Verbal Learning Test (Verbal Learning Memory Test, VLMT, [35]). The VLMT is a widely used neuropsychological test of verbal learning and memory with only minor requirement of language and 


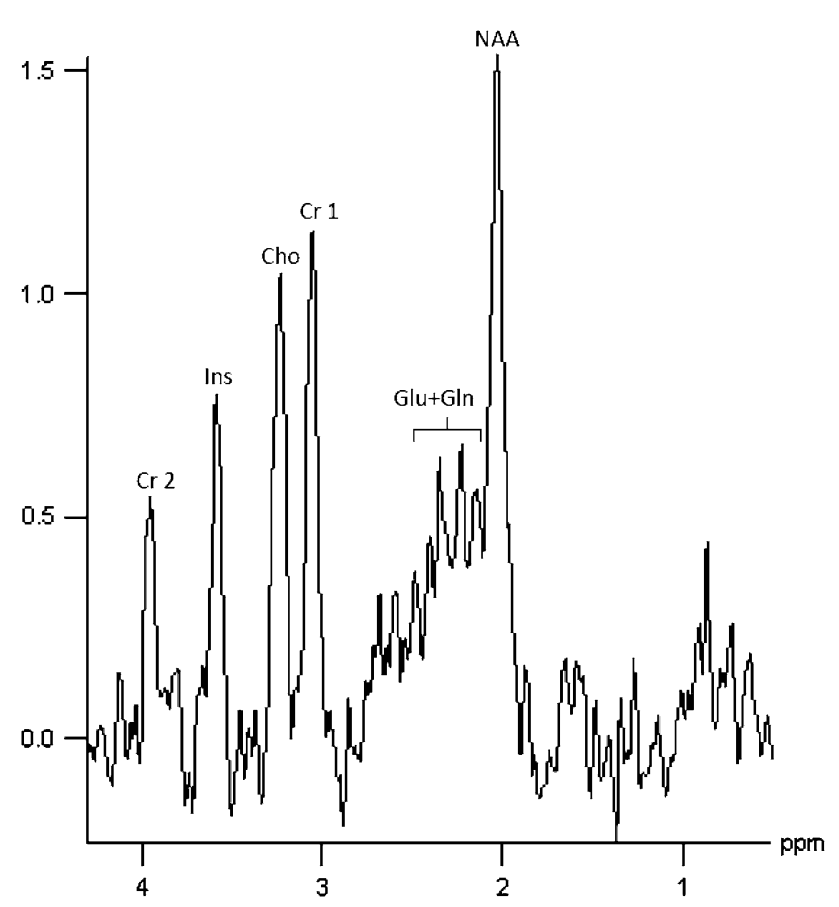

Fig. 2 Typical proton magnetic resonance spectroscopy spectrum (1H-MRS) from the left hippocampus

motor skills. This test allows the assessment of verbal declarative memory and investigates the encoding capacity, the direct and delayed recall performance and episodic recognition abilities [24].

\section{Genotyping}

DNA was extracted according to the salting out procedure [32]. The following primers were used in the polymerase chain reaction (PCR): 5'-AAAGCCCTAACCAGTTTTCT G-3' (forward) and 5'-TCCTCCAGCAGAAAGAGAAG-3' (reverse). The PCR was done in a $50 \mu \mathrm{l}$ reaction mixture containing $100 \mathrm{ng}$ of genomic DNA, $200 \mu \mathrm{M}$ of each dNTPs, 10 pmol of each primer, 0.5 units Taq-polymerase, and buffer $(\mathrm{KCl} 50 \mathrm{mM}$, Tris- $\mathrm{HCl} 10 \mathrm{mM}$, Tween 20 $0.025 \%$, BSA $0.025 \mathrm{mg} / \mathrm{ml}$, and $2.0 \mathrm{mM} \mathrm{MgCl} 2$ ). The PCR reaction had an initial temperature of $94^{\circ} \mathrm{C}(5 \mathrm{~min})$ followed by 35 cycles of denaturation $\left(94^{\circ} \mathrm{C}, 45 \mathrm{~s}\right)$, annealing $\left(58^{\circ} \mathrm{C}, 45 \mathrm{~s}\right)$, and extension $\left(72^{\circ} \mathrm{C}, 45 \mathrm{~s}\right)$. An extension period of $7 \mathrm{~min}$ at $72^{\circ} \mathrm{C}$ followed the final cycle. The PCRs were done using an ABI GeneAmp ${ }^{\circledR} 9700$ cycler.

PCR products were digested at $37^{\circ} \mathrm{C}$ using Pmll (NEB, Ipswich, MA, USA), separated on $2.0 \%$ agarose gels (ROTI ${ }^{\circledR}$ GAROSE NEEO, Roth, Karlsruhe), and genotyped according to the resulting fragment lengths. BDNF genotypes were called by two individuals being blind to the clinical data.
Statistics

For statistical analyses, SPSS for Windows 16.0 was used. Level of significance was set at $\alpha<0.05$. All tests were two-tailed. Only in cases in which analyses were based on a priori hypotheses derived from literature (e.g., [10, 41]), results are presented without correction of error probabilities for multiple testing (see also [41]).

In order to determine possible confounding variables, effects of age and duration of education on the dependent variables were assessed within the sample of healthy controls using Pearson product moment correlations, while one-way analysis of variance (ANOVA) was performed to examine the influence of the factors gender and handedness as well as (in the entire sample) of the factor diagnosis. For further analysis, the intervening variables education, age, gender, and diagnosis were included into the MANCOVA, as each of these intervening variables had a significant influence on some of the dependent variables.

Subjects of the three different groups (schizophrenia, bipolar I, and healthy controls) were separated according to the BDNF genotype into homozygous carriers of the valallele (val/val) or the met-allele (met/met), and heterozygotes (val/met). These genotype groups were compared to each other with regard to the dependent variables (i) relative hippocampal volumes (left and right), (ii) MRS ratios in the left hippocampus, and (iii) overall performance in the verbal learning memory test. For (i) a repeated measures MANCOVA with between-subject factors BDNF genotype, gender and diagnosis, within-subject factor side and covariates age and education was calculated. For (ii) MANCOVA and for (iii) ANCOVA with factor BDNF genotype and the intervening variables education, age, gender, and diagnosis were performed. In case of significant effects for the factor BDNF genotype in the MANCOVA, we performed post-hoc comparisons between groups in order to further evaluate the genetic effect. In particular, to evaluate the effects of only one met-allele, $\mathrm{val} /$ met heterozygotes were compared with val homozygotes (val/val). In order to address the effect of two metalleles, met homozygotes (met/met) were compared with val homozygotes (val/val).

To make our results more comparable to other studies, we calculated the effect sizes for the results of the ANOVA ( $f$ values).

\section{Results}

The frequency of the BDNF val/val genotype in the overall sample was $65 \%$ in schizophrenia patients and $54 \%$ in patients with bipolar I disorder, and $57 \%$ in healthy subjects, which is in accordance with previously published 
data. Overall, the genotype frequencies were in the HardyWeinberg equilibrium $(P=0.93)$.

BDNF effects on hippocampal volumes

The inter-rater reliability (intraclass correlation coefficient = ICC) and the intra-rater reliability for the volumetric hippocampal measurement was 0.93 and 0.99 , respectively. Repeated measures MANCOVA did not reveal any significant effect of the BDNF val66met polymorphism on relative hippocampal volume $(F(2$, $86)=0.50, P=0.61)$. Furthermore, MANCOVA did neither reveal a significant interaction side $\mathrm{x}$ BDNF nor diagnosis $\mathrm{x}$ BDNF.

BDNF effects on magnetic resonance spectroscopy markers in hippocampus, dorsolateral prefrontal, and frontomedian cortex

Initial MANCOVA (factor: BDNF, intervening variables education, age, gender, and diagnosis) showed a significant effect of BDNF val66met genotype on MRS ratios in the left hippocampus $(F(10,162)=1.91, P=0.048$, effect size: $f=0.342$ ), but not in the left dorsolateral prefrontal cortex $(F(10,176)=0.91, P=0.52)$ nor in the left posterior frontomedian cortex $(F(10,176)=0.65, P=0.77)$. For all the three regions, the interaction diagnosis $\mathrm{x}$ BDNF was not significant.

Post-hoc comparisons for BDNF genotype effects on MRS markers in the left hippocampus revealed that met/met homozygotes had significantly lower NAA/Cre $(-21.1 \% ; \quad F(1, \quad 52)=4.80, \quad P=0.033$, effect size: $f=0.303$ and $(\mathrm{Glu}+\mathrm{Gln}) / \mathrm{Cre}(-46.0 \% ; F(1,52)=6.20$, $P=0.016$, effect size: $f=0.346)$ ratios as compared with $\mathrm{val} / \mathrm{val}$ homozygotes (Fig. 3a, b), while the difference in the NAA/Cho ratio did not reach the level of significance $(-15.1 \% ; F(1,52)=1.78, P=0.185)$. Mean values of these MRS ratios in the heterozygous val/met group generally laid in between the two homozygous groups. However, no statistically significant effect for a reduction in the MRS ratios in the val/met group as compared with the val/ val homozygotes could be observed.

When all met-allele carriers (homozygotes and heterozygotes) were pooled and contrasted with val/val homozygotes, no significant differences in MRS ratios could be detected. The interaction diagnosis $\times$ BDNF did not show a significant effect.

BDNF effects on verbal memory

Consistent with previous studies on verbal memory, carriers of the met-allele numerically revealed a reduced overall performance (sum of five direct recalls) in the verbal
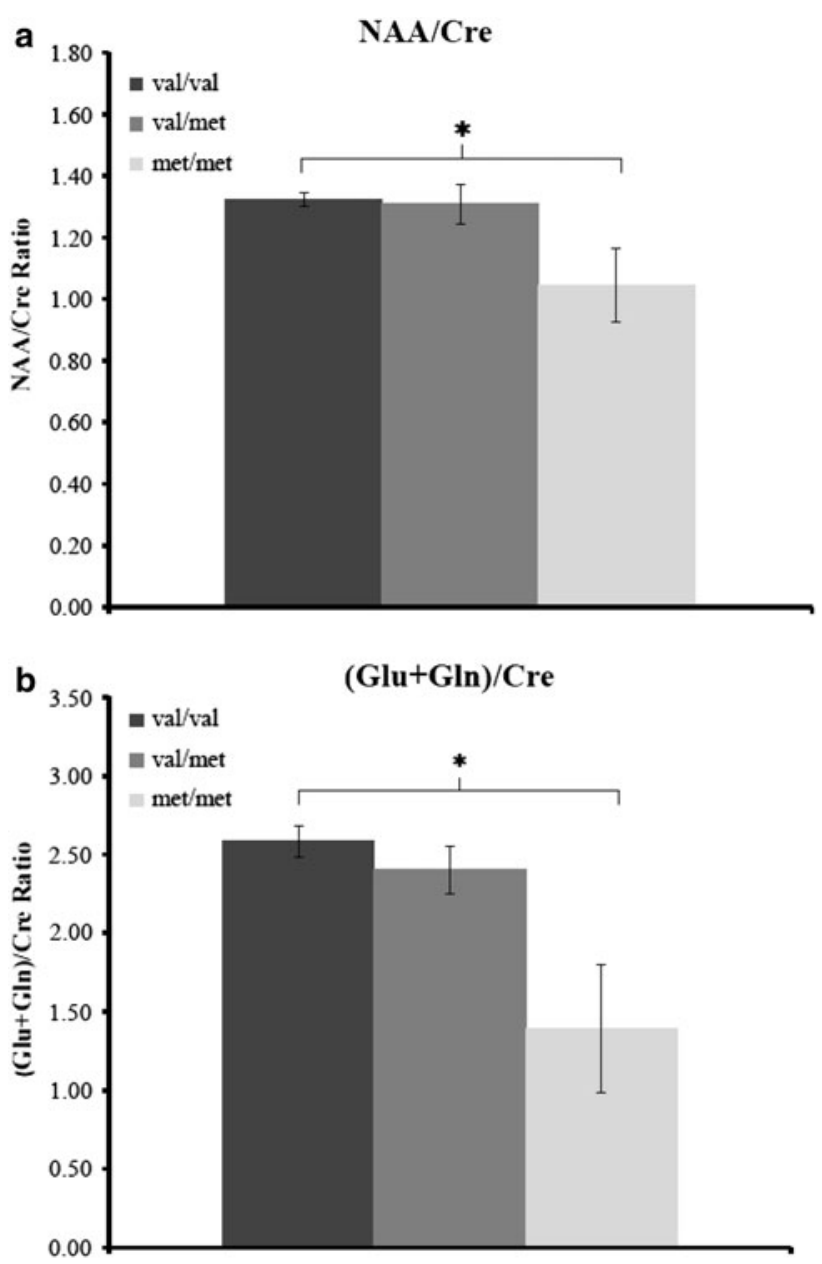

Fig. 3 Significant effects of the functional BDNF val66met polymorphism rs6265 on magnetic resonance spectroscopic markers (a NAA/ $\mathrm{Cre} ; \mathbf{b}(\mathrm{Glu}+\mathrm{Gln}) / \mathrm{Cre})$ in the left hippocampus. $* P<0.05$. The $y$-axis represents the ratios between NAA/Cre and (Glu + Gln)/Cre

learning memory test, but this did not turn out to be statistically significant in the ANCOVA $(F(2,98)=0.30$, $P=0.74$, effect size: $f<0.1$ ).

\section{Discussion}

In the present study, we investigated the impact of the functional BDNF val66met polymorphism on magnetic resonance spectroscopic markers (NAA/Cre, NAA/Cho, $\mathrm{Cho} / \mathrm{Cre}$, and (Glu $+\mathrm{Gln}) / \mathrm{Cre})$ in the left hippocampus, left dorsolateral prefrontal, and left posterior frontomedian cortex, as well as on hippocampal volumes and on verbal memory capacity in a group of 158 subjects (66 schizophrenia patients, $45 \mathrm{BD}$ patients, and 47 healthy controls). Our main finding was a significant effect of BDNF genotype on metabolic markers specifically in the left hippocampus. In particular, homozygous carriers of the 
met-allele exhibited significantly lower NAA/Cre and $(\mathrm{Glu}+\mathrm{Gln}) / \mathrm{Cre}$ metabolic ratios as compared with val/val homozygotes (Fig. 3). This effect was confirmed by controlling for identified intervening covariates. Although in the heterozygous val/met group, the mean values of these MRS ratios laid in between the two homozygous groups, no significant effect of the presence of only one met-allele could be detected in this group. Thus, our data suggest that BDNF effects on NAA/Cre and $(\mathrm{Glu}+\mathrm{Gln}) / \mathrm{Cre}$ ratios in the left hippocampus may be specific for (or at least most pronounced in) homozygous carriers of the met-allele. Alternatively, these effects may be present in heterozygotes for the met-allele as well, but may be too small to have reached the level of statistical significance in our sample.

Overall, these MRS results are consistent with previous reports of a significant reduction in left hippocampal NAA/ Cre and NAA/Cho levels in carriers of the BDNF rs6265 met-allele $[10,41]$. Thus, we were able to replicate these prior findings in an ethnically homogeneous sample of only caucasians. Furthermore, our data that were acquired in a mixed sample of both healthy subjects and psychiatric patients with psychotic disorders suggest that the observed BDNF genotype effects on MRS markers may be relatively independent of these psychiatric diagnoses as there were no effects of diagnosis on these markers and no genotype $\mathrm{x}$ diagnosis interactions. Moreover, our findings provide in vivo evidence for an effect of the functional BDNF polymorphism on glutamate levels in the left human hippocampus, which is consistent with the theory that BDNF may impact NAA via its influence on the glutamate system $[6,41]$.

Our negative MRS finding in the posterior frontomedian cortex seems to contradict the very recent observation of higher NAA levels in the anterior cingulate cortex of metallele carriers [13]. The authors interpreted this finding tentatively as an up-regulation of cingulate NAA to compensate decreasing hippocampal NAA in met-allele carriers. Several methodological differences may account for these partially discrepant results, such as the precise placement and the size of MRS voxels, the measurement of absolute versus relative metabolite concentrations and numerical as well as genetic differences between samples. For example, it is unclear whether and to what extent the rather large ACC voxel recorded by Gallinat and colleagues overlaps with our voxel in the posterior frontomedian cortex, which was anatomically precisely defined as (and adjusted to) the (left sided) cingulate cortex located dorsally and posterior to the genu of the corpus callosum along the cingulate sulcus (see [23], for a very similar voxel positioning, however, centered on the interhemispheric fissure). Functionally, this cortical region has been implicated in adaptive cognitive control of behavior, in particular in background monitoring of the environment for potentially significant sensory events [15]. Given the fact that BDNF effects on MRS markers appear to be regionally specific (as indicated by the present and other results), this highlights the importance of investigating clearly defined and (presumably) functionally homogeneous brain regions.

With regard to BDNF effects on brain structure, we were unable to replicate prior findings of a hippocampal volume reduction in carriers of the met-allele [12, 21, 37] as we did not find any effect of BDNF genotype on hippocampal volume. Thus, this negative finding is more consistent with other recent studies which also did not observe BDNF genotype effects on structural volumes of the hippocampus [33, 41]. While our finding further excludes that the observed BDNF effects on MRS markers might have resulted from confounding differences in hippocampus volume (see [41]), it is still possible that BDNF may also impact on hippocampal structure, but with lower effect size, which may not be observable in diagnostically heterogeneous samples. Furthermore, the results are compatible with the suggestion that neurochemical MRS markers may be more sensitive to BDNF genotype effects than volumetric measures [41]. Interestingly, one study showed that the BDNF val66met polymorphism is associated with temporal gray matter loss over 4 years in patients with Bipolar I Disorder [31]. Hence, it is possible that BDNF effects on brain structure may only be observable in longitudinal studies that assess changes in the course of brain disorders. However, in this context, it is worth to mention that schizophrenia and bipolar affective disorder share in parts a common pathophysiological pathway and display similar symptoms, but differ in the disease course and in the cortical gray matter loss [9, 34].

Finally, our finding of a numerical, but nonsignificant effect of BDNF genotype on verbal memory is quite consistent with previous reports of BDNF genotype effects on episodic memory and, to a lesser extent, on verbal memory $[5,10,16]$. As verbal memory tests like the California Verbal Learning Test (CVLT) and the Verbal Learning Memory Test (VLMT) may (in comparison to episodic memory tests) also impose considerable demands on prefrontal cortical functions, this may explain the lack of statistical significance for BDNF effects on the VLMT in the present study (for a similar discussion see Egan et al. 2003). Given the fact that BDNF is well-known to facilitate LTP, i.e., memory-related processes in the hippocampus [1, $5,8,10,12,21,22,36-38]$, further studies are definitely required to clarify possible effects of BDNF genotype on hippocampus-dependent cognition. A possible bias of these results might be the effects of concomitant medication on cerebral neurochemistry. This phenomenon is being controversially disputed by different authors, and there might be an effect of neuroleptics on cerebral NAA levels $[4,11$, 
18], although in the light of other studies, this appears to be unlikely $[18,26]$.

It can further be speculated whether our results are linked to the heritability of our outcome measures. Different studies point toward heritability of hippocampal volumetric measures, hippocampal spectroscopy parameters, and of verbal memory [20, 25, 30]. Our finding of a BDNF effect in a mixed sample of healthy controls and patients suffering from schizophrenia and BP is indeed compatible with the assumption of heritability of our outcome parameters.

In summary, the present findings provide further evidence for a crucial role of BDNF in hippocampal functioning. In this context, BDNF has been linked to hippocampus-related forms of learning and memory, in particular via its effects on activity-dependent changes in synaptic strength of glutamatergic synapses [3]. BDNF has been shown both to facilitate glutamate release at the presynapse and to increase postsynaptic glutamate receptor phosphorylation and synthesis [6]. In consideration of these findings, only recently, it had been hypothesized that BDNF may exert its observed effects on NAA via its influence on the glutamatergic system [41]. Consistent with this hypothesis, the present results provide first in vivo evidence for an effect of the functional BDNF val66met polymorphism on the glutamate system in human hippocampus. Furthermore, our data suggest that these BDNF effects on NAA and glutamate in the hippocampus may be most pronounced in homozygous carriers of the BDNF met-allele.

Conflict of interest O. G. was honorary speaker for the following companies: AstraZeneca, Bristol Myers Squibb, Janssen Cilag, Lilly, Otsuka. O. G. has been invited to scientific congresses by AstraZeneca, Janssen Cilag, Pfizer. A. H. has been invited to scientific congresses by AstraZeneca, Lundbeck, and Janssen Cilag. H. S. has accepted paid speaking engagements in industry-sponsored symposia from AstraZeneca, BMS, Eli-Lilly, Janssen Cilag, Pfizer and Servier, and travel or hospitality not related to a speaking engagement from AstraZeneca, BMS, Eli Lilly, and Janssen Cilag T. W. is a member of a speaker bureau for Alpine Biomed, AstraZeneca, Eli Lilly, Essex, Janssen Cilag; has accepted paid speaking engagements in industrysponsored symposia from Alpine Biomed, AstraZeneca, Bristol Myers Squibb, Eli Lilly, Janssen Cilag, Lundbeck, Sanofi-Aventis and Pfizer, and travel or hospitality not related to a speaking engagement from AstraZeneca, Bristol Myers Squibb, Eli Lilly, Janssen Cilag, and Sanofi-Synthelabo; and has received a research grant from AstraZeneca. T. S-A. reports no financial relationships with commercial interests S. E. reports no financial relationships with commercial interests. A. S. reports no financial relationships with commercial interests. M. B. reports no financial relationships with commercial interests. W. R. reports no financial relationships with commercial interests. J. M. reports no financial relationships with commercial interests. P. F. has accepted paid speaking engagements in industry-sponsored symposia from Janssen Cilag, AstraZeneca, Lilly, BMS, Lundbeck, Pfizer, Bayer Vital, SKB, Wyeth, and Essex. P. F. is member in the advisory board of Janssen Cilag, AstraZeneca, Lilly, and Lundbeck. Investigator initiated trial: AstraZeneca.
Open Access This article is distributed under the terms of the Creative Commons Attribution Noncommercial License which permits any noncommercial use, distribution, and reproduction in any medium, provided the original author(s) and source are credited.

\section{References}

1. Aicardi G, Argilli E, Cappello S, Santi S, Riccio M, Thoenen H, Canossa M (2004) Induction of long-term potentiation and depression is reflected by corresponding changes in secretion of endogenous brain-derived neurotrophic factor. Proc Natl Acad Sci USA 101:15788-15792

2. Ashburner J, Friston K (1997) Multimodal image coregistration and partitioning - a unified framework. Neuroimage 6:209-217

3. Bekinschtein P, Cammarota M, Izquierdo I, Medina JH (2008) BDNF and memory formation and storage. Neuroscientist 14:147-156

4. Bertolino A, Callicott JH, Mattay VS, Weidenhammer KM, Rakow R, Egan MF, Weinberger DR (2001) The effect of treatment with antipsychotic drugs on brain $\mathrm{N}$-acetylaspartate measures in patients with schizophrenia. Biol Psychiatry 49:39-46

5. Bueller JA, Aftab M, Sen S, Gomez-Hassan D, Burmeister M, Zubieta JK (2006) BDNF Val66 Met allele is associated with reduced hippocampal volume in healthy subjects. Biol Psychiatry 59:812-815

6. Carvalho AL, Caldeira MV, Santos SD, Duarte CB (2008) Role of the brain-derived neurotrophic factor at glutamatergic synapses. Br J Pharmacol 153(Suppl 1):S310-S324

7. Cheng CY, Hong CJ, Yu YW, Chen TJ, Wu HC, Tsai SJ (2005) Brain-derived neurotrophic factor (Val66Met) genetic polymorphism is associated with substance abuse in males. Brain Res Mol Brain Res 140:86-90

8. Chepenik LG, Fredericks C, Papademetris X, Spencer L, Lacadie C, Wang F, Pittman B, Duncan JS, Staib LH, Duman RS, Gelernter J, Blumberg HP (2009) Effects of the brain-derived neurotrophic growth factor val66met variation on hippocampus morphology in bipolar disorder. Neuropsychopharmacology 34:944-951

9. Cumming AG, Matthews NL, Park S (2010) Olfactory identification and preference in bipolar disorder and schizophrenia. Eur Arch Psychiatry Clin Neurosci [Epub ahead of print]

10. Egan MF, Kojima M, Callicott JH, Goldberg TE, Kolachana BS, Bertolino A, Zaitsev E, Gold B, Goldman D, Dean M, Lu B, Weinberger DR (2003) The BDNF val66met polymorphism affects activity-dependent secretion of BDNF and human memory and hippocampal function. Cell 112:257-269

11. Fannon D, Simmons A, Tennakoon L, O'Ceallaigh S, Sumich A, Doku V, Shew C, Sharma T (2003) Selective deficit of hippocampal $\mathrm{N}$-acetylaspartate in antipsychotic-naive patients with schizophrenia. Biol Psychiatry 54:587-598

12. Frodl T, Schule C, Schmitt G, Born C, Baghai T, Zill P, Bottlender R, Rupprecht R, Bondy B, Reiser M, Moller HJ, Meisenzahl EM (2007) Association of the brain-derived neurotrophic factor Val66Met polymorphism with reduced hippocampal volumes in major depression. Arch Gen Psychiatry 64:410-416

13. Gallinat J, Schubert F, Bruhl R, Hellweg R, Klar AA, Kehrer C, Wirth C, Sander T, Lang UE (2010) Met carriers of BDNF Val66Met genotype show increased N-acetylaspartate concentration in the anterior cingulate cortex. Neuroimage 49:767-771

14. Gruber O, Falkai P, Schneider-Axmann T, Schwab SG, Wagner M, Maier W (2008) Neuregulin-1 haplotype HAP(ICE) is associated with lower hippocampal volumes in schizophrenic patients and in non-affected family members. J Psychiatr Res 43:1-6 
15. Gruber O, Melcher T, Diekhof EK, Karch S, Falkai P, Goschke T (2009) Brain mechanisms associated with background monitoring of the environment for potentially significant sensory events. Brain Cogn 69:559-564

16. Hansell NK, James MR, Duffy DL, Birley AJ, Luciano M, Geffen GM, Wright MJ, Montgomery GW, Martin NG (2007) Effect of the BDNF V166M polymorphism on working memory in healthy adolescents. Genes Brain Behav 6:260-268

17. Hariri AR, Goldberg TE, Mattay VS, Kolachana BS, Callicott JH, Egan MF, Weinberger DR (2003) Brain-derived neurotrophic factor val66met polymorphism affects human memory-related hippocampal activity and predicts memory performance. J Neurosci 23:6690-6694

18. Harte MK, Bachus SB, Reynolds GP (2005) Increased N-acetylaspartate in rat striatum following long-term administration of haloperidol. Schizophr Res 75:303-308

19. Hashimoto R, Moriguchi Y, Yamashita F, Mori T, Nemoto K, Okada T, Hori H, Noguchi H, Kunugi H, Ohnishi T (2008) Dosedependent effect of the Val66Met polymorphism of the brainderived neurotrophic factor gene on memory-related hippocampal activity. Neurosci Res 61:360-367

20. Hasler G, Neumeister A, van der Veen JW, Tumonis T, Bain EE, Shen J, Drevets WC, Charney DS (2005) Normal prefrontal gamma-aminobutyric acid levels in remitted depressed subjects determined by proton magnetic resonance spectroscopy. Biol Psychiatry 58:969-973

21. Ho BC, Andreasen NC, Dawson JD, Wassink TH (2007) Association between brain-derived neurotrophic factor Val66Met gene polymorphism and progressive brain volume changes in schizophrenia. Am J Psychiatry 164:1890-1899

22. Ho BC, Milev P, O'Leary DS, Librant A, Andreasen NC, Wassink TH (2006) Cognitive and magnetic resonance imaging brain morphometric correlates of brain-derived neurotrophic factor Val66Met gene polymorphism in patients with schizophrenia and healthy volunteers. Arch Gen Psychiatry 63:731-740

23. Hoerst M, Weber-Fahr W, Tunc-Skarka N, Ruf M, Bohus M, Schmahl C, Ende G (2010) Correlation of glutamate levels in the anterior cingulate cortex with self-reported impulsivity in patients with borderline personality disorder and healthy controls. Arch Gen Psychiatry 67:946-954

24. Jamrozinski K, Gruber O, Kemmer C, Falkai P, Scherk H (2009) Neurocognitive functions in euthymic bipolar patients. Acta Psychiatry Scand 119:365-374

25. Kaymaz N, van Os J (2009) Heritability of structural brain traits an endophenotype approach to deconstruct schizophrenia. Int Rev Neurobiol 89:85-130

26. Klar AA, Ballmaier M, Leopold K, Hake I, Schaefer M, Bruhl R, Schubert F, Gallinat J (2010) Interaction of hippocampal volume and $\mathrm{N}$-acetylaspartate concentration deficits in schizophrenia: a combined MRI and 1H-MRS study. Neuroimage 53:51-57

27. Krebs MO, Guillin O, Bourdell MC, Schwartz JC, Olie JP, Poirier MF, Sokoloff P (2000) Brain derived neurotrophic factor (BDNF) gene variants association with age at onset and therapeutic response in schizophrenia. Mol Psychiatry 5:558-562

28. Maisonpierre PC, Le Beau MM, Espinosa R 3rd, Ip NY, Belluscio L, de la Monte SM, Squinto S, Furth ME, Yancopoulos GD (1991) Human and rat brain-derived neurotrophic factor and neurotrophin-3: gene structures, distributions, and chromosomal localizations. Genomics 10:558-568

29. Manahan-Vaughan D, Kulla A (2003) Regulation of depotentiation and long-term potentiation in the dentate gyrus of freely moving rats by dopamine D2-like receptors. Cereb Cortex 13:123-135

30. Marenco S, Radulescu E (2010) Imaging genetics of structural brain connectivity and neural integrity markers. Neuroimage 53:848-856

31. McIntosh AM, Moorhead TW, McKirdy J, Sussmann JE, Hall J, Johnstone EC, Lawrie SM (2007) Temporal grey matter reductions in bipolar disorder are associated with the BDNF Val66Met polymorphism. Mol Psychiatry 12:902-903

32. Miller SA, Dykes DD, Polesky HF (1988) A simple salting out procedure for extracting DNA from human nucleated cells. Nucleic Acids Res 16:1215

33. Miyajima F, Ollier W, Mayes A, Jackson A, Thacker N, Rabbitt P, Pendleton N, Horan M, Payton A (2008) Brain-derived neurotrophic factor polymorphism Val66Met influences cognitive abilities in the elderly. Genes Brain Behav 7:411-417

34. Molina V, Galindo G, Cortes B, de Herrera AG, Ledo A, Sanz J, Montes C, Hernandez-Tamames JA (2010) Different gray matter patterns in chronic schizophrenia and chronic bipolar disorder patients identified using voxel-based morphometry. Eur Arch Psychiatry Clin Neurosci

35. Muller H, Hasse-Sander I, Horn R, Helmstaedter C, Elger CE (1997) Rey auditory-verbal learning test: structure of a modified German version. J Clin Psychol 53:663-671

36. Patterson SL, Abel T, Deuel TA, Martin KC, Rose JC, Kandel ER (1996) Recombinant BDNF rescues deficits in basal synaptic transmission and hippocampal LTP in BDNF knockout mice. Neuron 16:1137-1145

37. Pezawas L, Verchinski BA, Mattay VS, Callicott JH, Kolachana BS, Straub RE, Egan MF, Meyer-Lindenberg A, Weinberger DR (2004) The brain-derived neurotrophic factor val66met polymorphism and variation in human cortical morphology. J Neurosci 24:10099-10102

38. Poo MM (2001) Neurotrophins as synaptic modulators. Nat Rev Neurosci 2:24-32

39. Scherk H, Backens M, Zill P, Schneider-Axmann T, Wobrock T, Usher J, Reith W, Falkai P, Moller HJ, Bondy B, Gruber O (2008) SNAP-25 genotype influences NAA/Cho in left hippocampus. J Neural Transm 115:1513-1518

40. Sklar P, Gabriel SB, McInnis MG, Bennett P, Lim YM, Tsan G, Schaffner S, Kirov G, Jones I, Owen M, Craddock N, DePaulo JR, Lander ES (2002) Family-based association study of 76 candidate genes in bipolar disorder: BDNF is a potential risk locus. Brain-derived neutrophic factor. Mol Psychiatry 7:579_ 593

41. Stern AJ, Savostyanova AA, Goldman A, Barnett AS, van der Veen JW, Callicott JH, Mattay VS, Weinberger DR, Marenco S (2008) Impact of the brain-derived neurotrophic factor Val66Met polymorphism on levels of hippocampal $\mathrm{N}$-acetyl-aspartate assessed by magnetic resonance spectroscopic imaging at 3 Tesla. Biol Psychiatry 64:856-862

42. Tamminga CA, Stan AD, Wagner AD (2010) The Hippocampal Formation in Schizophrenia. Am J Psychiatry 167(10):1178-1193

43. Tan YL, Zhou DF, Cao LY, Zou YZ, Wu GY, Zhang XY (2005) Effect of the BDNF Val66Met genotype on episodic memory in schizophrenia. Schizophr Res 77:355-356

44. Wittchen HU, Wunderlich U, Gruschwitz S, Zaudig M (1997) Strukturiertes Klinisches Interview für DSM-IV. Achse I: Psychische Störungen. A German, advanced adaptation of the original SCID version by RL Spitzer. JB Williams, M Gibbon and MB First. Hogrefe-Verlag, Göttingen 